\title{
Evaluation of oxidative and nitrosative stress in relapsing remitting multiple sclerosis
}

\author{
Štefan Lukáčč ${ }^{\star}$, Terézia Kalnovičová ${ }^{2}$, Jana Muchová ${ }^{1}$ \\ ${ }^{1}$ Institute of Medical Chemistry, Biochemistry and Clinical Biochemistry, Faculty of Medicine, Comenius University, Bratislava, Slovakia; \\ *Corresponding Author: stefanlukacjr@gmail.com \\ ${ }^{2}$ Department of Neurology, Faculty of Medicine, Comenius University, Bratislava, Slovakia
}

Received 17 September 2013; revised 28 October 2013; accepted 5 November 2013

Copyright (C) 2013 Štefan Lukáč et al. This is an open access article distributed under the Creative Commons Attribution License, which permits unrestricted use, distribution, and reproduction in any medium, provided the original work is properly cited.

\begin{abstract}
Multiple sclerosis (MS) is a chronic autoimmune disorder affecting the central nervous system (CNS) through demyelination and neurodegeneration. Several lines of evidence support a role for oxidative and nitrative stress (OS and NS) in pathogenesis of multiple sclerosis. The mechanism of influence of OS and NS on blood-brainbarrier (BBB) has critical importance for evaluating antioxidant therapies. As far as we know, markers of oxidative and nitrative stress in MS patients have been investigated independently for their relationship with the state of the bloodbrain-barrier. Blood plasma samples of 58 patients with relapse-remitting MS (RRMS) with normal (Group $A, n=48,36.2 \pm 10.5$ years) and damaged BBB (Group B, $n=10,38.2 \pm 11.2$ years) and of 44 healthy controls (39.2 \pm 14.9 years) were analyzed. TAS (total antioxidant plasma status), lipoperoxides, protein carbonyls, 3-nitrotyrosine and uric acid were evaluated in each group. Our results confirmed decreased TAS (Group A: $1.35 \pm 0.55 \mathrm{mmol} / \mathrm{l}, \mathrm{P}<0.001$; Group B: $1.73 \pm 0.37 \mathrm{mmol} / \mathrm{l}$ vs. $1.9 \pm 0.7 \mathrm{mmol} / \mathrm{l})$ and increased lipoperoxidation (A: $71.5 \pm 42.18$ $\mathrm{nmol} / \mathrm{ml}, \mathrm{P}<0.01$; $\mathrm{B}: 127.02 \pm 74.67 \mathrm{nmol} / \mathrm{ml}, \mathrm{P}<$ 0.001 vs. $46.6 \pm 27.4 \mathrm{nmol} / \mathrm{ml}$ ) in RRSM patients. The level of lipoperoxidation positively correlated with the state of BBB $(P<0.05)$. Elevated concentrations of protein's carbonyls (A: $0.48 \pm 0.11$ $\mathrm{nmol} / \mathrm{mg}$ protein, $\mathrm{P}<0.001$; $\mathrm{B}: 0.43 \pm 0.14 \mathrm{nmol} / \mathrm{mg}$ protein, $\mathrm{P}<0.05 \mathrm{vs}$. $0.31 \pm 0.01 \mathrm{nmol} / \mathrm{mg}$ protein) and 3-nitrotyrosine $(A: 107.3 \pm 40.7 \mathrm{nmol} / \mathrm{l}, \mathrm{P}<$ 0.001 ; B: $89.2 \pm 15.9 \mathrm{nmol} / \mathrm{l}, \mathrm{P}<0.001$ vs. $21.6 \pm$ $3.7 \mathrm{nmol} / \mathrm{l})$ indicated free-radical mediated damage to plasma proteins, what was confirmed by their positive mutual correlation $(P<0.001)$.
\end{abstract}

The level of uric acid was physiological and correlated negatively with protein's carbonyls $(P<$ 0.05 ) while there was no significant relationship with 3-nitotyrosine. The results suggest the role of this antioxidant in the protection of the proteins against $O S$ what was confirmed by its positive correlation with TAS $(P<0.05)$. It could be concluded that ROS/RNS in MS patients affect a wide range of substances, change their properties and function. High concentration of lipoperoxides indicates a role of lipid peroxidation in deterioration of BBB. Considering the body complexity, extremely high levels of damaged proteins in blood plasma and abnormal state of BBB should lead us to assumption of changed proteins in CNS that can activate immune system and result into autoimmune response. Therefore, it is necessary to pay attention to ROS/RNS reduction in therapeutic process to reduce damage to BBB and other adverse effects.

Keywords: Relapsing Remiting Multiple Sclerosis; Oxidative Stress; Nitrative Stress;

Blood-Brain-Barrier; Total Antioxidant Status; 3-Nitrotyrosine; Protein Carbonyls;

Lipoperoxides; Uric Acid

\section{INTRODUCTION}

Multiple sclerosis (MS) is a demyelinating autoimmune disease of the central nervous system (CNS). The etiology of MS is not known, but there are many risk factors and predispositions described in the literature. Nowadays the most accepted theory suggests that the disease occurs mostly in people with genetic predisposition and could be initiated by viral infection [1]. Recent studies describe the important role of the oxidative stress 
(OS) in pathogenesis of demyelination and inflammation $[2,3]$. In the field of OS and neurodegeneration, peroxinitrite is one of the most important free radicals. It has been accepted that the molecules of peroxynitrite are the final molecules responsible for pathological processes in neurodegenerative diseases and MS [3]. Reactive oxygen and nitrogen species are produced by microglia that is activated by T-lymphocytes, especially $\mathrm{T}_{\mathrm{H}}-17$ cells in the reactions of immune response to antigen. Radicals attack different molecules, cause their damage leading to the loss of their function with negative effects on the neural tissue what could enhance progress of the disease. One of the undesired impacts is the deterioration of the bloodbrain barrier (BBB) that creates unphysiological state between the CNS and the rest of the body leading to horrible consequences. Therefore, it is necessary to evaluate pro- and antioxidative status in these patients due to $\mathrm{BBB}$ state.

\section{AIM}

The aim of our study was to detect total antioxidant status of plasma (TAS) in patients with MS, to analyze various markers of oxidative damage, their mutual correlations and correlations with the state of the bloodbrain barrier. We also monitored the level of natural antioxidant-uric acid (UA), which concentration in plasma of MS-patients is currently leading discussions.

\section{MATERIALS AND METHODS}

Blood plasma samples from 58 patients with diagnosed multiple sclerosis according to McDonald's rules were analyzed. The tested group was divided into group with normal and pathological state of blood-brain barrier according to QA-index. Group A with normal state of BBB consisted of 29 females and 19 males with average age $36.2 \pm 10.5$ years. Group B with damaged BBB included 7 females and 3 males with average age $38.2 \pm$ 11.2 years. Every patient had relapsing-remitting form and was out of relapse. According to our knowledge, patients did not suffer from any other disease that would affect markers of oxidative/nitrative stress. Control group consisted of 44 healthy people with average age $39.2 \pm$ 14.8 years ( 24 males and 19 females). Every participant signed informed consent and agreed with the investigation of mentioned parameters. Statement of ethical committee was not necessary since examination of parameters was indicated by the neurologist and was a component of diagnostic process. None of them had demyelinating disease or other diseases associated with an increase in oxidative stress. State of BBB of MS-patients was evaluated via QA-index, as ratio between albumin concentration in cerebrospinal fluid and in blood plasma multiplied by 1000; QA index higher than 7.4 indicates blood-brain barrier deterioration. TAS was analyzed by TEAC method according to Re, et al. [4]. This method measures the presence of hydrophobic and hydrophilic antioxidants in blood plasma. Oxidative damage to lipids was detected by the rate of lipid peroxidation according to el-Saadani, et al. [5]. To detect protein's damage OS and nitrative stress (NS) was evaluated via level of protein's carbonyls and 3-nitrotyrosine. Carbonyls were determined by ELISA method by Buss et al. [6] and the level of 3-nitrotyrosine was analyzed by commercial ELISA test $\left[\mathrm{Hycult}^{\mathbb{B}}\right.$, Netherlands]. Impact of oxidative damage on metabolism of purine bases was evaluated by measuring the concentration of uric acid by HPLC method (high performance liquid chromatography) with UV detection. After deproteination (with $8 \% \mathrm{HClO}_{4}$ ) and centrifugation $\left(10,000 \mathrm{~g}, 20 \mathrm{~min}, 0^{\circ} \mathrm{C}-4^{\circ} \mathrm{C}\right)$ sample was injected into HPLC system. As a standard UA with concentrations $0.1 ; 0.25 ; 0.5 ; 0.75 \mu \mathrm{mol} / 1$ was used. Mobile phase included: $2 \%(\mathrm{v} / \mathrm{v})$ methanol in $80 \mathrm{mmol} / 1 \mathrm{KH}_{2} \mathrm{PO}_{4}$, pH 5.1; fluid speed: $0.8 \mathrm{ml} / \mathrm{min}$, column $250 \times 4 \mathrm{~mm}$ Nucleosil 120 - 5 C18 (Watrex, Czech Republic). The relationships among studied parameters and with the state of BBB were detected, too. Our results are represented as the mean value $\pm \mathrm{SD}$. The data that did not show a deviation from normality were evaluated by one way ANOVA with Bonferroni's multiple test and Student T-test for uric acid concentration. The Pearson test was used to determine the relationship among the parameters. Statistical evaluation was performed by Stats Direct 2.3.7 (Stats Direct Sales, Sale, Cheshire M33 3UY, United Kingdom). $\mathrm{P}<0.05$ was considered significant.

\section{RESULTS}

The summary of our results is presented in Table 1. We found out significantly reduced TAS of the patients with MS in both groups $(1.35 \pm 0.55 \mathrm{mmol} / \mathrm{l}$ in Group A and $1.73 \pm 0.37 \mathrm{mmol} / \mathrm{l}$ in Group B) in comparison to

Table 1. Level of some markers of oxidative stress in patients with MS and healthy controls.

\begin{tabular}{cccc}
\hline & Group A & Group B & Controls \\
\hline $\begin{array}{c}\text { TAS } \\
{[\mathrm{mmol} / \mathrm{l}]}\end{array}$ & $1.35 \pm 0.55^{* * *}$ & $1.73 \pm 0.37$ & $1.9 \pm 0.7$ \\
$\begin{array}{c}\text { Lipoperoxides } \\
{[\mathrm{nmol} / \mathrm{ml}]}\end{array}$ & $71.5 \pm 42.18^{* * * *}$ & $127.02 \pm 74.67^{* * *}$ & $46.62 \pm 27.36$ \\
$\begin{array}{c}\text { Carbonyls } \\
{[\mathrm{nmol} / \mathrm{mg} \text { protein }]} \\
\begin{array}{c}\text { 3-Nitrotyrosine } \\
{[\mathrm{nmol} / \mathrm{l}]}\end{array}\end{array}$ & $0.48 \pm 0.11^{* * *}$ & $0.43 \pm 0.14^{*}$ & $0.31 \pm 0.01$ \\
\hline
\end{tabular}

Values are expressed as average $\pm \mathrm{SD}$. We compared A, B groups to controls group: $\left({ }^{*} \mathrm{P}<0.05\right) ;\left({ }^{* *} \mathrm{P}<0.01\right) ;\left({ }^{* * *} \mathrm{P}<0.001\right)$ and $\mathrm{A}$ versus $\mathrm{B}$ group: $(\mathrm{P}<0.05)$; ( $" \mathrm{P}<0.01) ;($ ( $\mathrm{P}<0.001)$. Group A: patients with MS, normal state of BBB; Group B: patients with MS, pathological state of BBB; TAS: total antioxidant status. 
healthy subjects $(1.9 \pm 0.7 \mathrm{mmol} / \mathrm{L})$. Statistically significant difference was confirmed only between group $\mathrm{A}$ and the control group, $\mathrm{P}<0.001$. We did not observe intergender differences. Concentration of lipoperoxides in plasma showed a significant difference between MS-patients and the controls. While the concentration of lipoperoxides in normal subjects was $46.62 \pm 27.36 \mathrm{nmol} / \mathrm{ml}$, in MS-patients: Group A $71.5 \pm 42.18 \mathrm{nmol} / \mathrm{mL}, \mathrm{P}<0.01$ and Group B $127.02 \pm 74.67 \mathrm{nmol} / \mathrm{ml}, \mathrm{P}<0.001$. We have noticed also the difference between patients groups, $\mathrm{P}<0.01$ and significantly higher rate of lipid peroxidation in men than in women, $\mathrm{P}<0.05$. The average concentration of 3-nitrotyrosine was significantly increased in both patients' groups: $107.32 \pm 40.74 \mathrm{nmol} / 1$ in Group A, $\mathrm{P}<0.001$, resp. $89.21 \pm 15.93 \mathrm{nmol} / 1$ in Group B, $\mathrm{P}<$ 0.001 , in comparison to control group $21.57 \pm 3.67$ $\mathrm{nmol} / \mathrm{l}$. The occurrence of protein carbonyls in patients with MS was: Group A $0.48 \pm 0.11 \mathrm{nmol} / \mathrm{mg} P$ (protein), $\mathrm{P}<0.001$, Group B $0.43 \pm 0.14 \mathrm{nmol} / \mathrm{mg} \mathrm{P}, \mathrm{P}<0.05$, while in plasma of healthy subjects, only $0.31 \pm 0.01$ $\mathrm{nmol} / \mathrm{mg}$ P. UA level was analyzed separately for men and women, because there are gender differences of its physiological concentrations. Concentration of uric acid in males was $380.41 \pm 86.57 \mu \mathrm{mol} / 1$ and in females 298.86 $\pm 56.11 \mu \mathrm{mol} / 1$ which is in the physiological range for both genders.

One of significant correlations was between the state of BBB and lipoperoxidation $(\mathrm{r}=0.289, \mathrm{n}=58, \mathrm{P}<0.05)$

(Figure 1). Analyzing the relations between tested parameters, positive correlation was confirmed between TAS and uric acid concentration $(\mathrm{r}=0.308, \mathrm{n}=58, \mathrm{P}<$ 0.05 ) (Figure 2) and another correlation between protein damage marker-protein carbonyls and 3-nitrotyrosine $(\mathrm{r}$ $=0.436, \mathrm{n}=58, \mathrm{P}<0.001)$ (Figure 3). There was a negative relationship between UA concentration and protein carbonyls $(\mathrm{r}=-0.328, \mathrm{n}=58, \mathrm{P}<0.05)$ (Figure 4).

\section{DISCUSSION}

To present study describes elevated values of various oxidative/nitrative stress markers in multiple sclerosis patients with different state of blood-brain barrier. Oxidative resp. and nitrative stress are important factors, which play a role in demyelination-associated changes and neurodegenerative disorders such as MS [3,8]. In accordance with other studies [3,7-9], we found a reduced TAS in MS patients. Low levels of antioxidants in blood plasma might indirectly point out to their high consumption by free radicals, which could be a proof of prooxidative processes in the body of MS patients [8,9]. Free radicals are not only products of cell metabolism, but also tools of leukocytes in immune intervention. Radicals attack molecules of all matters and could cause their damage and loss of function. Lipids are widely spread in

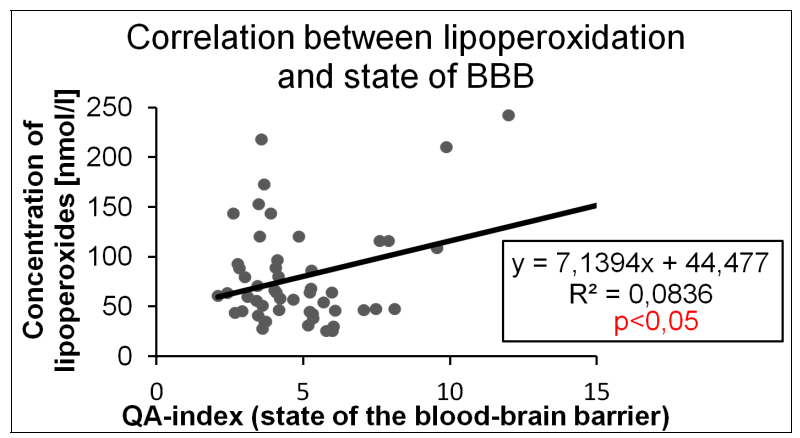

Figure 1. Correlation between lipoperoxidation and state of BBB.

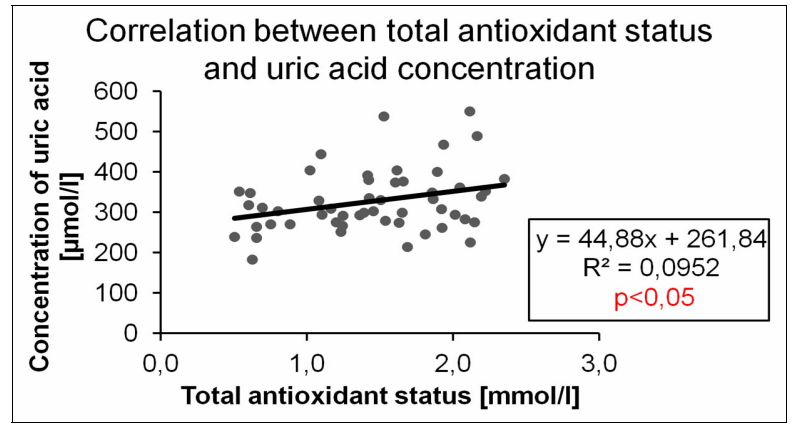

Figure 2. Correlation between total antioxidant status and uric acid concentration.

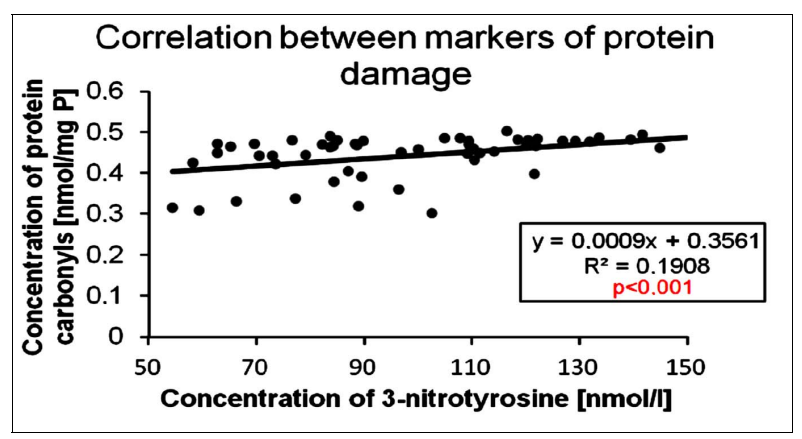

Figure 3. Correlation between markers of protein damage.

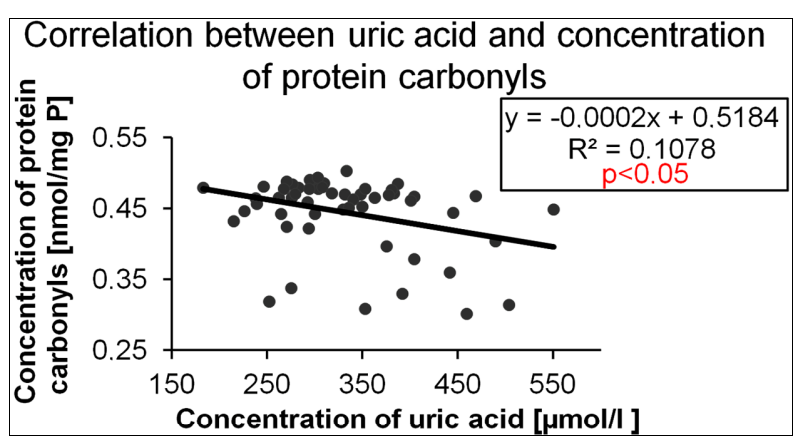

Figure 4. Correlation between uric acid and concentration of protein carbonyls.

human body as a major part of all cell membranes. These also form important barriers, as blood-brain barrier that 
should protect brain and its structures from undesired effects. Elevated lipoperoxidation in both patient groups, positively correlating with the state of BBB (Figure 1), could indicate an important role of free radicals in the disease progression. Free radicals could attack lipids in membrane of astrocytes, damage phospholipids' bilayer whereby reduce their function and function of the whole barrier [10].

In MS patients, we also observed a significant increase in another marker of oxidative damage, protein carbonyls. Previous studies $[8,16]$ indicate that plasma proteins are mostly damaged, but when we consider the integrity of the body, deteriorated BBB, we could also think about damaged proteins in the CNS.

3-nitrotyrosine is an indicator of increased formation of peroxynitrite and the most important molecule considered to be in charge of demyelination [3]. In agreement with literature data [11], significantly increased plasma levels of 3-nitrotyrosine were reported in our groups of MS patients. It may reflect the significant damage to neurons in the CNS when we use similar consideration as in protein carbonyls. Also mutual correlation between 3-nitrotyrosine and carbonyls (Figure 3) could show the negative effects of both types of free radicals on proteins. Proteins with changed structure have reduced functions and could also provide epitopse to enhance or induce the immune response which would be another negative effect on disease progression.

In the published literature there were found different levels of uric acid in MS-patients. Some of them describe higher, some lower and some unchanged concentration of uric acid in these patients $[11,13]$. Our results indicate concentration of uric acid in physiological range, but showed a tendency for higher values. According to our opinion, increased levels of uric acid in MS patients could cause elevated destruction of oligodendrocytes [12] and their nuclei. Human organism could react in this way on the inadequate formation of free radicals since uric acid is a natural antioxidant. Antioxidant function of UA is confirmed by its positive correlation with TAS (Figure 2) and negative correlation with protein carbonyls (Figure 4), although there was no significant correlation with 3-nitrotyrosine. We think that it could be explained by UA's property to scavenge mainly oxygen reactive species.

So far, there is no any effective prevention or therapeutic intervention known that would avoid the pathological processes of MS. A certain contribution to this issue also represents our study that confirmed the lack of anti-oxidant capacity of plasma in MS-patients caused by deficiency of hydrophilic and hydrophobic antioxidants. Elevated production of oxygen and nitrogen free radicals results in increased oxidative and nitrative stress with impact on many important molecules in the human body.
This fact should be taken into account in therapeutic practice. In addition, supplementation of both deficient antioxidants and whole-body cryotherapy can be effective to decrease OS [14]. There are new studies describing possibilities to reduce oxidative damage via antioxidant pathway action [15], but it is still uncertain whether reactive oxygen and nitrogen species are causes or consequences of autoimmune answer. Products of the free radical action could be in future one of the markers of disease progression, as it is actually speculated in some of the studies $[8,16]$. Oxidative stress is just one of many factors that negatively affect this disease. It is therefore necessary to pay attention to all other pathogenic aspects and their reduction to provide the patients with MS the best possible quality of life with untreatable disease.

\section{REFERENCES}

[1] Noseworthy, J.H. (1991) Progress in determining the causes and treatment of multiple sclerosis. Nature, 399, 40-47. http://dx.doi.org/10.1038/399a040

[2] Gonsette, R.E. (2008) Neurodegeneration in multiple sclerosis: The role of oxidatvie stress and excitotoxicity. Journal of the Neurological Sciences, 274, 48-53. http://dx.doi.org/10.1016/j.jns.2008.06.029

[3] Sayre, L.M., Perry, G. and Smith, M.A. (2008) Oxidative stress and neurotoxicity. Chemical Research in Toxicology, 21, 172-188. http://dx.doi.org/10.1021/tx700210j

[4] Re, R., Pellegrini, N., Protteggente, A., Pannala, A., Yang, M. and Rice-Evans, C. (1999) Antioxidant activity applying an improved ABTS radical cation decolorization assay. Free Radical Biology \& Medicine, 26, 1231-1237. http://dx.doi.org/10.1016/S0891-5849(98)00315-3

[5] el-Saadani, M., Esterbauer, H., el-Sayed, M., Goher, M., Nassar, A.Y. and Jurgens, G. (1989) A spectrophotometric assay for lipid peroxides in serum lipoproteins using a commercially available reagent. Journal of Lipid Research, 30, 627-630.

[6] Buss, H., Chan, T.P., Sluis, K.B., Domigan, N.M. and Winterbourn, C.C. (1997) Protein carbonyl measurement by a sensitive ELISA method. Free Radical Biology \& Medicine, 23, 361-366.

http://dx.doi.org/10.1016/S0891-5849(97)00104-4

[7] Uttara, B., Singh, A.V., Zamboni, P. and Mahajan, R.T. (2009) Oxidative stress and neurodegenerative diseases: A review of upstream and downstream antioxidant therapeutic options. Current Neuropharmacology, 7, 65-74. http://dx.doi.org/10.2174/157015909787602823

[8] Besler, H.T. and Comoglu, S. (2003) Lipoprotein oxidation, plasma total antioxidant capacity and homocysteine level in patients with multiple sclerosis. Nutritional Neuroscience, 6, 189-196. http://dx.doi.org/10.1080/1028415031000115945

[9] Miller, E., Mrowicka, M., Saluk-Juszczak, J. and Majsterek, I. (2011) The level of isoprostanes as a non-invasive marker for in vivo lipid peroxidation in secondary 
progressive multiple sclerosis. Neurochemical Research, 36, 1012-1016.

http://dx.doi.org/10.1007/s11064-011-0442-1

[10] Frei, B., Stocker, R. and Ames, B.N. (1988) Antioxidant defences and lipid peroxidation in human blood plasma. Proceedings of the National Academy of Sciences of USA, 85, 9748-9752. http://dx.doi.org/10.1073/pnas.85.24.9748

[11] Miller, E., Walczak, A., Saluk, J., Ponczek, M.B. and Majsterek, I. (2012) Oxidative modification of patient's plasma proteins and its role in pathogenesis of multiple sclerosis. Clinical Biochemistry, 45, 26-30. http://dx.doi.org/10.1016/j.clinbiochem.2011.09.021

[12] Kuračka, L. (2011) Association between degradation products of purine nucleotides in cerebrospinal fluid and levels of some lipofilic vitamins in plasma of patients with multiple sclerosis. Proceedings of the 50th Faculty Conference of Student Science Work, 6th Scientific Conference of Graduants MF CU, 14 April 2011, Bratislava, 6770.

[13] Amorini, A.M., Petzold, A., Tavazzi, B., Eikelenboom, J.,
Keir, G., Belli, A., Giovannoni, G., Di Pietro, V., Polman, C., D’Urso, S., Vagnozzi, R., Uitdehaag, B. and Lazzarino, G. (2009) Increase of uric acid and purine compounds in biological fluids of multiple sclerosis patients. Clinical Biochemistry, 42, 1001-1006.

http://dx.doi.org/10.1016/j.clinbiochem.2009.03.020

[14] Miller, E., Mrowicka, M., Malinowska, K., Mrowicki, J., Saluk-Juszczak, J. and Kedziora, J. (2009) Effects of wholebody cryotherapy on oxidative stress in multiple sclerosis patients. Journal of Thermal Biology, 35, 406-410. http://dx.doi.org/10.1016/j.jtherbio.2010.08.006

[15] Virgili, N., Mancera, P., Wappenhans, B., Sorrosal, G., Biber, K., Pugliese, M. and Espinosa-Parrilla, J.F. (2013) KATP channel opener diazoxide prevents neurodegeneration: A new mechanism of action via antioxidative pathway activation. PLoS One, 11, 8-9.

[16] Sadowska-Bartosz, I., Adamczyk-Sowa, M., Galiniak, S., Mucha, S., Pierzchala, K. and Bartosz, G. (2013) Oxidative modification of serum proteins in multiple sclerosis. Neurochemisty International, 63, 507-516. 